\title{
Promoting population health by integrating an interprofessional poverty simulation into the curriculum
}

\author{
Katie Hooven* \\ Department of Nursing, The College of New Jersey, United States
}

Received: November 14, 2018

DOI: $10.5430 /$ jnep.v9n5p52

\author{
Accepted: January 4, 2019 \\ Online Published: January 17, 2019 \\ URL: https://doi.org/10.5430/jnep.v9n5p52
}

\begin{abstract}
Background: Nursing programs have a unique opportunity to bolster students' understanding of the concept of population health management through use of a poverty simulation. Addressing population health requires that nurses understand the broader issues impacting patient care. Aim: To determine if integrating an interprofessional poverty simulation is an effective tool to introduce the concept of population health management.

Methods: The Community Action Poverty Simulation(C) was implemented in a baccalaureate nursing curriculum as an interprofessional learning activity. The study was quasi-experimental using a quantitative pre-test and post-test design and qualitative essays.

Results: Data were collected from 277 college students, including 149 nursing majors.

Conclusions: The analyses support that a published poverty simulation is an effective resource to expose students to interprofessional collaboration and establish a professional precedent to promote population health management principles.
\end{abstract}

Key Words: Population health, Poverty simulation, Interprofessional, Nursing education

\section{INTRODUCTION}

Adequate provision of population-based healthcare requires additional knowledge and skills not typically addressed in baccalaureate curricula sufficiently for students to develop proficiency. Providing population-based healthcare also requires that nurses:

(a) comprehend the broader social issues such as income, education, employment, and physical environment that are responsible for influencing and defining health,

(b) are able to intervene with solutions or suggestions from a broader perspective as well as using existing evidence based practices, and

(c) are able to organize accessible community resources to encourage better health outcomes. ${ }^{[1,2]}$

As a concept, population health is generally described as the health outcomes of a group of individuals, including the sharing of such health outcomes within the group. Hallmarks of population health are that it ensures that patients' needs and preferences are met over time with respect to health services and information sharing across people, functions, and sites, and that patient care activities are organized between two or more participants, including the patient, to facilitate the appropriate delivery of healthcare services. ${ }^{[3]}$

The healthcare delivery system continues to undergo tremendous change. ${ }^{[4]}$ Nurses, being the largest sector of healthcare

*Correspondence: Katie Hooven; Email: hoovenk@tcnj.edu; Address: Department of Nursing, The College of New Jersey, United States. 
professionals, have the unique ability to be at the forefront of this change. With the reimbursement structure changing for hospital systems, healthcare is shifting from an emphasis on disease management in acute care settings to an emphasis on health promotion and reduction of co-morbidities in the community. This change in emphasis affords educational institutions an opportunity to focus on care that requires coordination, an understanding of trends, and use data to create population-based interventions. One cannot expect nurses who have focused all their clinical years being acute care Registered Nurses (RN) to be able to understand and apply population health principles and practice interprofessionally without giving them a practical understanding. Giving nursing students the opportunity to participate in the The Community Action Poverty Simulation(c) (CAPS) could create a professional precedent and insight into nursing students' future as nurses. Although the poverty simulation has been documented as effective in increasing an awareness to poverty in nursing students, ${ }^{[5,6]}$ it has not been recognized for supporting population health management.

\begin{abstract}
Aim
The focus of this project emerged from an integrative framework that incorporated nursing, public health, and other disciplines to break down the silos that affect patient outcomes. The research question the baccalaureate nursing faculty wanted to answer was: Is integrating an interprofessional poverty simulation an effective tool to introduce the concept of population health management?
\end{abstract}

\section{METHOD}

\subsection{Sample}

Demographic data were purposefully limited to maintain confidentiality. Analysis was done using IBM SPSS Statistics (version 24; SPSS, IBM Inc., Armonk, NY, USA). Significance was set at $p<.05$. The paired $t$-test results were calculated using data from the pre- and post-tests. A total of 189 participants [nursing $(n=113)$, public health $(n=66)$ and other $(n=10)$ ] completed the qualitative reflection.

\subsection{Setting}

The setting for this study was a primarily undergraduate, residential liberal arts college with targeted graduate programs. Prior to beginning the study, Institutional Review Board approval was secured. Although the participating students were required to complete the simulation as part of a class, students could opt in or out of the pre-test, post-test or both. The design of the study was quasi-experimental research utilizing pre and post-tests. The CAPS was implemented on four occasions at (institution) between November 2016 and March 2017.

Published by Sciedu Press

\subsection{Simulation}

The Community Action Poverty Simulation(C) (CAPS) is a simulation designed by the Missouri Action Committee to bring a better understanding of the experiences of life in poverty. The simulation can be run for 90 research participants plus an additional 15-20 community members from specific agencies. In order to run the simulation, the facilitator attended additional training as part of the simulation purchase through the Missouri Action Committee. Research participants were assigned a role of a person who must navigate the system for a simulated "month" over a 2-hour period. As the simulation plays out, each family must successfully acquire the basic needs for one month by completing tasks such as paying rent, buying food, going to work or school, and traveling to community resources to meet their needs. Each week was represented by a 15-minute time period when community resources are open, and a three minute weekend to discuss and strategize with the rest of their family unit. Simulation community organizations and businesses were staffed with local community members who had first-hand experience living in poverty. ${ }^{[7]}$ After the simulation was completed, there was a 30-45 minutes debriefing that started with a few scripted questions and led to a discussion where both the students and the community volunteers shared their personal experiences and what they experienced during the simulation. This debriefing allowed for open dialog and gave students an opportunity to ask questions in a safe environment. The simulation and the debriefing emphasized the issues of accessibility, systems based problems, finances, and the coordination of daily efforts in order to survive. All of these issues are population health concerns and relevant to the broader society.

\subsection{Tools}

Data were collected using the online Qualtrics system (Qualtrics, LLC, Provo, UT, USA) from students who participated in the CAPS(C). The pre-test post-test questionnaire that was distributed following the poverty simulation had 16 questions and came from the CAPS(C) program to assess students' knowledge and attitudes about poverty. Questions were scored on a five point Likert type scale with five being "strongly reflects what I believe or know" and one being "strongly does not reflect what I believe or know." Likert-like option seven read "do not know" and option eight was "do not understand the question." These choices gave the option to not have a forced response. A few Likert type questions included were:

- The social service system in America only has a positive impact on those it serves;

- The community provides effective and efficient service to help families with low income survive; and 
- People with low income have low self-esteem.

The pre- and post-tests were matched based on an anonymous identification number selected by the students. The pre-test was done within one to three weeks prior to the simulation, and the post-tests were completed within two weeks after the CAPS(C) simulation. An open-ended question, "After participating in this simulation, how will this experience impact the way you interact with students, clients, or patients in the future?" was asked on the post-test to further describe the participant's thoughts and feelings.

\subsection{Data analysis}

A total of 349 (institution) students participated in the CAPS. Information collected on the participants is shown in Table 1. Quantitative Data was analyzed and presented for all interprofessional students who participated in the study, while the qualitative analyses focused specifically on the nursing students and the influence the simulation had on shaping their clinical practice.

The questionnaire had a total of 16 items and the researchers looked at the item means individually. Three of the questions were not evaluated because they were most focused on poverty knowledge facts that were unrelated to the study purpose. For the total group, 11 out of the $13(84.62 \%)$ questionnaire items had a statistically significant change in response after students participated in the CAPS(C). The positive change indicated an increased awareness or knowledge of the item specific content (see Table 2).
Table 1. Demographics

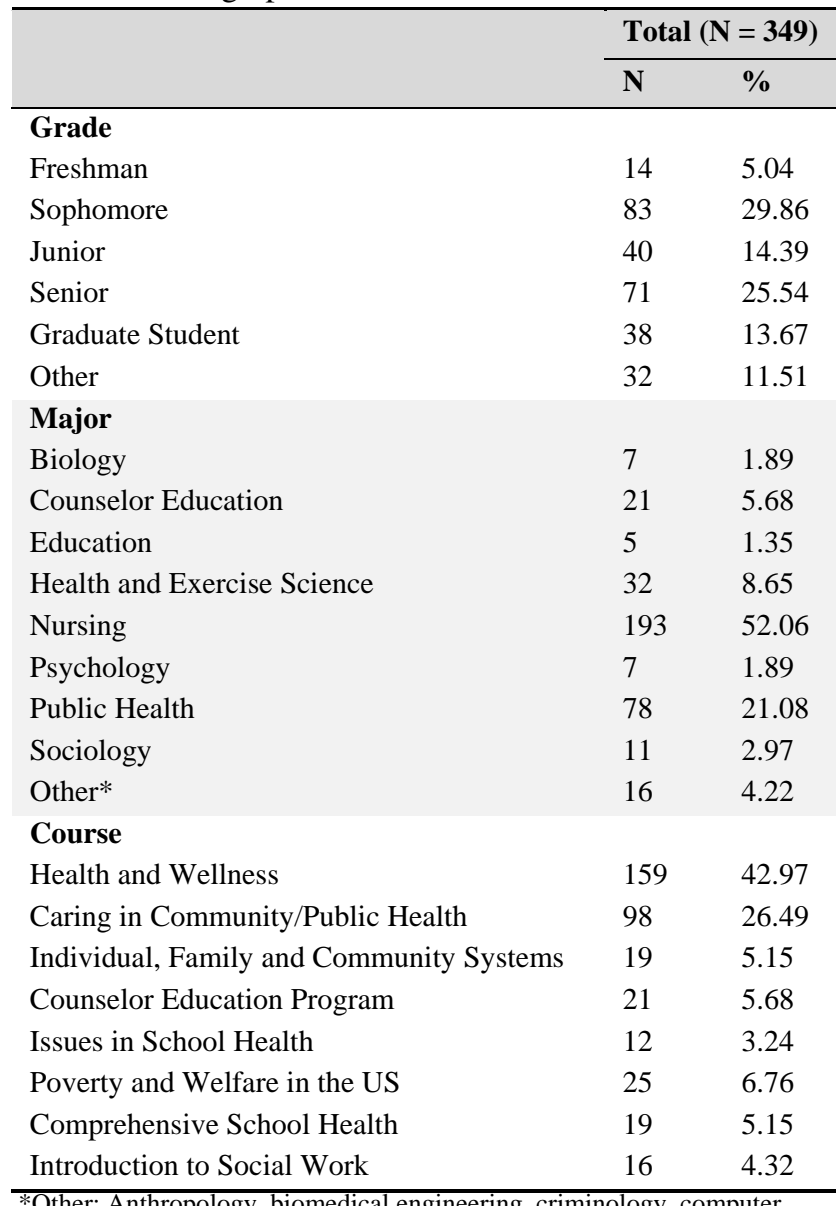

*Other: Anthropology, biomedical engineering, criminology, computer science, economics, physics, social work, nondisclosed

Table 2. Poverty questionnaire response changes

\begin{tabular}{|c|c|c|c|c|c|}
\hline \multirow{2}{*}{ Variable } & \multicolumn{2}{|c|}{ Pre-Simulation } & \multicolumn{2}{|c|}{ Post-Simulation } & \multirow{2}{*}{ Change in Means } \\
\hline & Mean & SD & Mean & SD & \\
\hline Q1 & 3.14 & 0.91 & 2.93 & 1.19 & $-0.21 *$ \\
\hline Q2 & 1.84 & 0.98 & 1.59 & 0.95 & $-0.25^{*}$ \\
\hline Q3 & 2.02 & 1.02 & 1.75 & 0.99 & $-0.27 *$ \\
\hline Q4 & 2.05 & 1.06 & 1.70 & 0.94 & $-0.35^{*}$ \\
\hline Q5 & 1.99 & 0.95 & 1.74 & 0.96 & $-0.25^{*}$ \\
\hline Q6 & 2.45 & 1.00 & 1.98 & 1.02 & $-0.47 *$ \\
\hline Q8 & 3.80 & 1.28 & 4.06 & 1.34 & $0.26^{*}$ \\
\hline Q9 & 2.54 & 1.00 & 2.39 & 1.01 & $-0.15^{*}$ \\
\hline Q10 & 2.06 & 1.00 & 1.92 & 1.06 & $-0.14^{*}$ \\
\hline Q12 & 1.67 & 0.85 & 1.57 & 0.88 & -0.10 \\
\hline Q13 & 2.31 & 1.13 & 2.08 & 1.15 & $-0.23^{*}$ \\
\hline Q15 & 1.98 & 0.95 & 1.84 & 0.99 & -0.14 \\
\hline Q16 & 2.98 & 1.11 & 3.21 & 1.17 & $0.23 *$ \\
\hline
\end{tabular}

*Statistically significant change in means, $p<.05$. 
Qualitative data were collected and analyzed with NVivo version 11 (QSR International Pty Ltd., Doncaster, Victoria, Australia). Responses were coded by collapsing similar reactions and then further combining categories with related ideas. This allowed the researcher to reflect on the ways people discussed particular topics, confirmed relationships, and developed their experiences. ${ }^{[8]}$ For the nursing students, there were two main response categories. The first category was an "understanding" and the second category was a "call to action".

\section{RESUltS}

The first response category related to students having a better "understanding" of the struggles of poverty. Students whose responses fell into this category were able to empathize with a population most had never thought about. Students wrote about how this group of patients may need more support than other patients. For example, students wrote: "I will not make snap judgments about people," and "When I see 'non-compliant' with meds, I will ask more specifically why.'

Other statements that were echoed in many of the responses were:

"I will make sure to understand the living situation my patients are returning to."

"This is important in order to make sure my patients get the treatments, follow up, or care that they need after discharge."

"It is important to know what resources are available for each patient so we can best help them to utilize those resources (or help connect them with new ones)."

Care coordination represents a major portion of what nurses need to do to promote population health. This poverty simulation made participants more understanding of this care coordination role. The topics encountered in the simulation were not strictly related to people living in poverty. Rather, the poverty simulation gave students a broader perspective of common struggles that all of their patients may endure. One student related this simulation to the current population they serve in stating: "With my employment at a psychiatric hospital, I feel like this simulation created more awareness for me in how important social services can be as part of a collaborative treatment team." Another student related the simulation to a population based problem with the lack of accessibility of resources.

"I now understand how accessibility overall can impact patient healthcare decisions. If a patient does not have transportation to be able to get to where they need to be then they are left untreated regardless of their intent."

The second response category related to the "call to action" and what in their practice would change after participating in the simulation. Students recognized the need for connecting people with community services and how most of these services were not as easy to utilize as students had previously thought. Another sentiment under this theme was the need to have a better understanding of patient needs and knowledge deficits. This quote succinctly summarizes the connection between the simulation and population health: "Additionally, patient teaching must go beyond the surface and address the bigger issues, and nurses must be able to understand how the environment and circumstances affect a patient's health."

\section{Discussion}

Prior to the simulation, the majority of participants believed many of the false stereotypes they were asked to be true; these beliefs, including that low-income people are lazy and do not work hard, one's economic status is completely under their own control, and the ability to live comfortably off social services and government handouts, are representative how many non-poor Americans view those living in poverty. ${ }^{[9]}$ After the simulation experience of life in poverty, the participants were more knowledgeable about real life in poverty. The largest changes in attitudes came with regards to why low income people have not improved their situation and the ability to live off of social services and charitable aid. By better understanding the daily struggles of America's poor and the role of and access to social services, professionals can provide better aid to those they interact with. It is essential for professionals to perform their job with a broad scope. In the case of health care, often providers only see the disease that presents in front of them; in education, teachers often punish students for acting out or not completing their homework. Through a broader understanding of the spectrum of impacts and stressors people living in poverty deal with, professionals across a multitude of disciplines can work with more compassion and be more effective with their intended outcomes.

As experienced by the participants, life in poverty is extremely difficult and stressful. These stressors have impacts on every aspect of life, including one's health, ${ }^{[10]}$ mental health, ${ }^{[11]}$ educational achievement, ${ }^{[12]}$ and job retention and performance, which all impact one's ability to rise above poverty. Through this experience, future professionals are more empathetic to those they interact with and more willing to work within the context of the person's situation to accomplish goals. For example, health care professionals 
with a better understanding of population-based health and how their patients live will lead to better health outcomes, ${ }^{[13]}$ or teachers with a better understanding of a child's home life and higher social-emotional competence will lead to better grades, and higher high school retention rates. ${ }^{[14]}$ By better understanding the unique stressors people in poverty face, professionals across many disciplines can better serve the people they interact with, in hopes of raising their socioeconomic status.

In this study, simulation was an effective method for improving knowledge and beliefs on poverty. While the literature shows that simulation is an effective method of education for nurses, doctors, and other health care professionals, ${ }^{[15]}$ this simulation was also effective in improving knowledge and beliefs for student participants in non-health care fields. Since health care professionals are not the only ones who deal with those living in poverty, educating a multitude of different professionals on this topic could greatly impact the poverty cycle. This educational simulation has specifically important implications for teachers, school counselors, and other professionals who work with children, as education and keeping impoverished children in school is a major key in breaking the poverty cycle. ${ }^{[12]}$ Interprofessional education has clear benefits across disciplines.

\section{Limitations}

This study had several limitations. First, not all of the students competed the long qualitative reflection $(51.29 \%$ response rate); the majority of the qualitative responses came from sophomore and senior level nursing and freshmen public health students. Students with other backgrounds might have had additional commentary that might have differed from those who responded. Second, the study was originally designed as a part of the nursing curriculum that also houses the public health program at (the institution), explain- ing why $53.8 \%$ of the sample were nursing students. Finally, qualitative data regarding future implications for workplace behavior of future professionals is speculative; further longitudinal research would need to be conducted to determine long term impacts of the program and if actions of the future professionals match their intentions. Moving forward the simulation will continue to run across all departments and data will be collected as it was previously for comparison.

\section{Conclusions}

Currently, nursing is considered the largest body of healthcare workers, ${ }^{[16]}$ which gives nurses a unique advantage to contribute to better patient outcomes. Multiple goals of nursing are to promote health and wellness and care for and educate those who are not at optimum health. As was uncovered in the literature, the use of the CAPS (C) to enhance student understanding of poverty already has been shown to be successful. ${ }^{[5,6]}$ The connectedness of this poverty simulation to promote population health principles is not documented. A major recommendation after implementing and evaluating this simulation is the importance and necessity of an experience such as this in baccalaureate nursing programs. The interprofessional nature of the poverty simulation allowed nursing students the ability to not only be the patient, but to participate as a larger group of patients trying to navigate life and the healthcare system. The simulation also gave students the opportunity to connect with their future professional colleagues from other disciplines and local community volunteers who donate their time to provide insight and education. Giving the nursing students the opportunity to participate in the CAPS $($ c poverty simulation hopefully has created a professional precedent to apply knowledge into practice and an insight into their future as nurses.

\section{CONFlicts OF INTEREST Disclosure}

The author declares that there is no conflict of interest.

\section{REFERENCES}

[1] Alper J. Population Health Implications of the Affordable Care Act: Workshop summary. Washington, D.C.: National Academies Press; 2014.

[2] Frenk J, Chen L, Zurayk H, et al. Health Professionals for a New Century: Transforming Education to Strengthen Health Systems in an Interdependent World. Lancet. 2010 Dec 4; 376(9756): 1923-58.

[3] American Nurses Association. White Paper: The Value of Nursing Care Coordination. 2012. Available from: http://www.nurs ingworld.org/carecoordinationwhitepaper Accessed April 29, 2017.

[4] Durrani H. Healthcare and healthcare systems: inspiring progress and future prospects. Mhealth. 2016; 2: 3.
[5] Noone J, Sideras S, Gubrud-Howe P, et al. Influence of a Poverty Simulation on Nursing Student Attitudes Toward Poverty. J Nurs Educ. 2012; 51(11): 617-622. PMid:22978272 https ://doi.org/ 10.3928/01484834-20120914-01

[6] Patterson N, Hulton L. Enhancing Nursing Students' Understanding of Poverty Through Simulation. Public Health Nurs. 2012; 29(2): 143-151. PMid:22372451 https://doi.org/10.1111/j.1525 $-1446.2011 .00999 . \mathrm{x}$

[7] Community Action Poverty Simulation. Available from: http: //www.povertysimulation.net/

[8] Morse M, Richards L. Read me first for a user's guide to qualitative methods. Thousand Oaks, CA: Sage; 2002.

[9] Henry J, Reyna C, Weiner B. Hate welfare but help the poor: How the 
attributional content of stereotypes explains the paradox of reactions to the destitute in America. Journal of Applied Social Psychology. 2004; 34(1): 34-58. https: //doi .org/10.1111/j.1559-1816. 2004.tb02536.x

[10] Adler N, Stewart J. Health disparities across the lifespan: meaning, methods, and mechanisms. Annals of the New York Academy of Sciences. 2010; 1186(1): 5-23. PMid:20201865 https://doi.or $\mathrm{g} / 10.1111 / \mathrm{j} .1749-6632.2009 .05337 . \mathrm{x}$

[11] Bland R. Poverty and mental illness, Thinking about Poverty. Federation Press. 2006; 131-141.

[12] Murnane J. Improving the education of children living in poverty. Future Child. 2007; 17: 161-182. https ://doi .org/10.1353/fo c. 2007.0019

[13] Marmot M. Commission on Social Determinants of Health. Achieving health equity: from root causes to fair outcomes. The Lancet.
2007; 370(9593): 1153-1163.

[14] Jennings P, Greenberg T. The prosocial classroom: Teacher social and emotional competence in relation to student and classroom outcomes. Review of Educational Research. 2009; 79(1): 491-525. https://doi.org/10.3102/0034654308325693

[15] Steadman H, Coates C, Huang M, et al. Simulation-based training is superior to problem-based learning for the acquisition of critical assessment and management skills. Critical Care Medicine. 2006; 34(1): 151-157. https://doi.org/10.1097/01. CCM.0000190 619.42013 .94

[16] Future of Nursing: National Nursing and Healthcare Workforce Data Meeting White Paper. Website. Available from: https://campaignforaction.org/wpcontent/uploads/20 16/11/May_2016_Nursing_Data_Workforce_Meeting-Whi tePaper_11_2016.pdf 